\title{
The Development of Design and Evaluation Guidelines of Convenient Equipments of Farm Work for the Elderly
}

\author{
Byung Chang Son ${ }^{1}$, Seung Heon Shin ${ }^{2}$ \\ ${ }^{1}$ Department of Rehabilitation Engineering, The University of Korea Nazarene, Cheonan, 331-718 \\ ${ }^{2}$ Department of Management Engineering, The University of Keimyung, Daegu, 704-701
}

\begin{abstract}
Objective: This study is to develop a design and evaluation guide to the ergonomic design of the farm working convenient equipments in order for the elderly to use them easily and safely. Background: The aging population has already increased in farm villages. But due to the usage of the farm working equipments that did not reflect the characteristics and functional changes of aging, accidents and patients with disease are increasing. Method: The study investigated the functional changes and physical, cognitive, and sensuous characteristics of the aged. By determining the criteria for classification of the convenient equipments by crop, and by finding out the items necessary for the ergonomic design, a guide to this study is proposed. Results: It is obvious that the physical, cognitive and sensuous functions change as the aging process continues. Therefore, for the design and evaluation of Control Panel, Control Lever, Frame Size, Shape, and Equipment Weight that are the necessary items for the ergonomic approach for the farm working equipments, such characteristics have to be reflected. Conclusion: Through this study, a guide to the design and evaluation of convenient equipments for the farm works that reflected the aging characteristics and functional changes has been proposed. Application: The result of this study is to expect not only designers but also related specialists to make the best use of it.
\end{abstract}

Keywords: Aging, Farm Working Convenient Equipment, Design Guide, Evaluation Guide

\section{Introduction}

근래 우리나라 농촌지역이 안고 있는 문제점은 여러 가지 가 있겠지만, 고령화에 따른 안전사고와 근골격계 질환 환 자의 증가가 주목을 받고 있다. 우리나라 인구의 고령화 현 상을 살펴보면 전체인구 중 65 세 이상인 자가 차지하는 비 율이 2005년에 9.1\%가 되어 UN이 정하는 고령화 사회에 진입하였으며 2018년에는 14.3\%로 고령사회, 2025년에는 $20.7 \%$ 로 초고령 사회에 진입할 것이라고 전망하고 있다 (Statistical Korea, 2010). 그러나 농촌지역의 고령화 현상 을 조사한 보고에 따르면 농촌지역은 이미 2007년도에 고 령자 비율이 $22.2 \%$ 넘어서 초고령 사회로 진입한 것으로
나타나 고령화 현상으로 인한 여러 문제들의 대책 마련이 도시지역보다 더욱 시급함을 알 수 있다(Statistical Korea, 2008).

농업 현대화의 영향으로 농작업의 많은 부분에 농기계가 보급되어 있다. 계속되는 농기계의 보급에 따라 사고도 증 가하고 있는데 전국농업인 중 491명을 대상으로 한 설문 조사에 따르면 이중 206명(41.9\%)이 농기계에 의한 안전 사고의 경험이 있는 것으로 조사되었다(Korea Consumer Agency, 2009). 특히 농촌지역에서는 안전사고 대부분 이 고령자들에게서 발생하고 있는 것으로 보고되고 있다 (Gyeongsangnam-do Inhabitants Daily Report, 2011). 농촌지역 고령자들의 안전사고와 함께 대두되는 또 다른 문제는 소위 농부증이라 일컫는 근골격계 질환 환자들의 증

Corresponding Author: Byung Chang Son. Department of Rehabilitation Engineering, The University of Korea Nazarene, Cheonan, 331-718.

Mobile: 010-2537-3531, E-mail: bcson@kornu.ac.kr

Copyright@2011 by Ergonomics Society of Korea(pISSN:1229-1684 eISSN:2093-8462). All right reserved. 
가이다. 근골격계 질환(Muscloskeletal disorders)이란 특 정신체 부위 및 근육의 부적절하고 과도한 사용으로 근육, 관절, 건, 인대, 인대 등에 손상이 발생하여 목, 어깨, 팔, 손 목, 손가락, 허리, 다리 등에 나타나는 만성적인 건강장애로 정의된다(Son et al., 2010). 농업인 건강 및 농작업 관리형 태(2009) 보고에 의하면 근골격계 질환자의 신체 부위별 유병율은 허리(57.0\%), 다리(56.3\%), 어깨(45.5\%)로 부 적절한 작업자세와 작업방법 등에 기인하고 있으며 일반산 업에 비해 유병율이 2.5 배나 높게 발생하고 있다. 이러한 문 제를 해결하기 위하여 2008년부터 농촌진흥청에서 농작업 편이장비 보급사업을 실시하고 있다. 이것은 비교적 큰 농기 계를 사용할 수 없는 좁은 장소와 간단한 작업에 인력을 대 체하거나 보조할 수 있는 장비를 보급하여 근골격계 질환 환자의 발생을 억제하고 생산성을 높이는 효과가 있다고 할 수 있다. 그러나 장비의 제작업체들이 대부분 영세하여 작업 자의 기능과 안전을 고려하여 제작하기가 어렵기 때문에 컨 설팅 전문가에 의하여 기존의 장비를 수정 - 보완하여 보급 하도록 하고 있으나 전문가들 사이에 시각차가 존재하고, 표 준화된 수정 지침이나 편이장비의 평가 지침이 없어 혼란이 발생되고 있는 것이 현실이다.

인간을 위한 기기는 그들의 신체적, 인지적, 감각적 특성 에 맞게 설계되어야 안전하고 편리하게 사용할 수 있다. 노 화에 따른 영향으로 여러 기능들이 저하하고 있는 고령자를 위한 장비 설계에 있어서는 더욱 그러하다. 그러나 우리나라 농기계 대부분은 고령자를 위한 배려가 미흡하여 사용이 불 편할 뿐만 아니라 안전사고의 위험도 있으며 실제로 사고로 이어지고 있다. 그러므로 본 연구에서는 노화에 따른 신체적, 인지적, 감각적 기능의 변화와 관련된 선행 연구들 중에서 장비의 설계와 평가에 필요한 요소를 추출하고 이를 바탕으 로 고령자를 위한 편의 장비의 설계와 평가에 손쉽게 활용할 수 있는 지침을 제안하고자 한다.

\section{Functional Changes with Aging}

\subsection{Physical functions}

노화가 진행됨에 따라 체형이 변화하고 이와 함께 심폐지 구력, 근력, 유연성, 평형성, 반응시간 등에 변화에 변화가 나타난다. 문헌에 의하면 노화에 따른 체형 변화의 경향은 높이항목은 작아지고 너비항목이 커지며 앞으로 굽는 체형 으로 변화하는데 Lee and Kim(2007), Size Korea(2011) 의하면 20 24세의 남성에 비해 60 69세의 남성은 키가 약 $4.6 \%$, 앉은 무릎 높이도 약 $5.6 \%$ 작았으며, 팔 길이에 있어서도 약 $2.4 \%$ 정도 짧은 것으로 나타났다. 이러한 경향
은 여성들에 있어서도 유사하였다. 엉덩이 너비는 남성이 약 $2.3 \%$ 작아졌으나, 여성은 약 $0.9 \%$ 정도 커진 것으로 나타 났다.

노화에 따른 골격근의 구조와 기능적 변화는 노인의 직무 수행에 영향을 준다. Vandervoort(1992)는 노화가 진행될 수록 수의적 생성시킬 수 있는 근력이 $80 \%$ 까지 감소한다고 하였고, Larsson(1978)은 근력이 50세까지는 비교적 잘 유지되나 50 세에서 70 세까지는 10 년 경과마다 $15 \%$ 씩 감 소하는 것으로 보고하였다. Danneskiod-Samson et al. (1984)은 70 80세부터는 근력 감소가 $30 \%$ 에 이르는 것 으로 보고하였다. 손의 근력에 관한 연구(Son and Shin, 2002)에서도 60대 여성은 30대 여성에 비해 약 $15.6 \%$ 정도 근력이 감소하는 것으로 조사되었다.

노화에 따른 신체적 변화가 근력 감소뿐만 아니라 행동적 으로도 몇 가지 변화가 나타나는데 불안한 자세, 느리고 허 둥대는 동작, 지척거리는 걸음걸이 등이 있다. 이러한 노화 의 행동적인 특성은 단지 근육의 노화에 영향을 받는 것이 아니라 시각, 청각, 피부 및 운동 감각의 기능저하와 밀접한 관계가 있다(Brown, 1996). 그러므로 이러한 영향으로 인 한 동작의 변화도 살펴볼 필요가 있다. 노인 집단과 청년집 단의 동작 계획의 명세화를 비교한 연구(Stelmach et al., 1987,1988 )에 의하면 노인 집단이 청년 집단에 비해 반응 시간이 길어진다고 하였고, 동작 계획의 재구성에 관련한 연 구(Amrhein et al., 1993)에서는 노인 집단이 반응시간이 길며 방향 변수와 관련한 동작 계획의 어려움이 있다고 보 고하고 있다. 반응시간 지연의 원인에 관한 연구(Cho and $\mathrm{Kim}, 2000$ )에서는 노인과 청년 집단 모두 동작제어를 위한 기본 기제는 유사하나 노화에 따른 운동체계의 잡음발생, 지 각적 피드백의 처리속도 지연, 동작 수행시 정확성에 대한 집착과 보수성, 근력생성의 절대역치 감소를 요인이라고 하 였다. 특히 한국 노인의 반응시간을 연구한 결과에 의하면 20대 남성에 비해 60대 남성은 0.6 0.7초 정도의 반응시간 지연을 나타낸다고 하였다(Seo and Lee, 1992).

\subsection{Cognitive functions}

정상적인 노화과정에서도 뇌의 기능 감소는 일반적인 현 상이며, 주의집중 장애나 망각 등 다양한 인지적 결함이 대 부분의 연령에 따른 뇌 기능 감퇴와 관련이 있는 것으로 보 고되고 있다(Park, 2004). Schneider and Pichora-Fuller (2000)은 연령에 따른 인지 기능의 감퇴가 주변시나 운동 지각 등과 같은 고등수준의 시각과정에도 나타난다고 하였 으며, McDowd and Shaw (2000)은 이러한 감퇴가 분할주 의와 같이 주의를 요하는 작업에서 더욱 두드러진다고 하 였다. 
노화가 기억에 미치는 영향은 기억체계에 따라 다르게 나 타나는데 기억체계 중 노화의 영향을 가장 크게 받는 것은 일화기억이며(Yonelinas, 2002), 의미기억, 절차기억, 암묵 기억은 영향을 거의 받지 않는 것으로 간주되고 있다(Voie and Light, 1994; Wingfield and Kahana, 2002). 단기기억 과제와 작업기억의 집행 기능이 요구되는 때에는 연령의 효 과가 두드러지며, 노인의 경우 망각하여야 할 정보를 더 잘 기억하는 특징이 있다는 연구도 보고되고 있다(Zacks et al., 2000). 언어능력과 추론능력은 60대 이후까지도 유지되지 만 기억력은 30 대부터 저하되며 노인의 기억력 저하는 다른 인지 기능보다 명확한 사실로 받아들여지고 있다(Craik and Tulving, 1975; Wechsler, 1987; Craik, 1991).

\subsection{Sensory functions}

인간의 행동과 적응 현상은 외부로부터 받아들인 정보들 을 대뇌에서 적절하게 해석한 결과라고 볼 수 있다. 시각기 관을 통한 외부정보는 약 $80 \%$ 이며 청각기관은 약 $15 \%$, 나 머지 기관에서 약 $5 \%$ 의 정보를 차지한다.

노화가 진행됨에 따라 동공크기 감소로 인해 시야(visual field) 가 좁아지며(Corso, 1992), 수정체가 두꺼워지고 모 양근의 기능이 약화되면서 수정체의 조절능력이 감소한다. 이 때문에 가까운 물체의 지각이 어려워지는데 40세 정도에 서의 근점거리는 $25 \mathrm{~cm}$ 를 넘지 않지만 50 세의 경우 $40 \mathrm{~cm}$ 가 되고 60 세의 경우 $1 \mathrm{~m}, 70$ 세의 경우 $4 \mathrm{~m}$ 정도까지 증가 한다(Goldstein, 1984). 원거리의 물체를 파악하는 20/20 vision의 비율을 보면 60세의 경우 $40 \%$ 미만이고, 70 세는 $30 \%$ 미만, 80 세에는 $10 \%$ 미만으로 기능이 저하되며 정적 인 물체보다 동적인 물체의 파악이 어렵다(Reading, 1972). 수정체 두께 증가로 이물질이 생기면 색체지각의 변화가 나 타나게 되는데, 장파장의 빛에너지(적색에서 황색)보다 단 파장의 빛에너지(자색에서 청색)의 자극에 문제가 발생하게 된다(Weale, 1986). Coren and Girgus(1972)에 의하면 60 대의 수정체는 장파장의 빛에너지를 젊은 시절과 비교하 여 약 $2 / 3$ 에서 $9 / 10$ 정도 통과시키지만 단파장의 빛에너 지는 약 $1 / 5$ 에서 $2 / 3$ 정도 밖에 통과시키지 못한다 하였다. Lee and Lee(2006)은 Yellow와 blue에 대한 색지각의 정확도 파악검사에서 yellow에 대한 색지각이 blue에 대한 지각보다 정확하며, blue가 red보다 green과 혼합된 경우 색의 변화를 지각하기 어렵다고 하였다. 성별로는 여성 노인 이 남성보다 색지각 능력이 더욱 감소하는 것으로 나타났다. 색지각 능력의 감소는 색 변화에 대한 감지가 어렵다는 것을 의미하며 색 자체의 지각에는 문제가 없는 것으로 생각할 수 있다. 연령 증가에 따라서 조도 변화에 적응하는 능력도 감 소하는데 80 세 고령자의 경우 20 대의 청년과 비교하면 정
상적으로 물체를 파악하기 위하여 약 200배의 조도가 필요 하다는 연구도 있다(Corso, 1981).

노화에 따른 청력 변화를 보면 60세 이상의 노인층은 저 주파에서 고주파로 갈수록 청력 역치가 상승하는데 이는 노화로 인한 외유모세포(outer hair cell)의 변성과 기저막 (basilar membrane) 운동성이 감소한 것이 원인으로 지목 되고 있으며(Park et al., 2006) 청력 역치의 증가율은 나이 에 따라 가속도가 생기는 것으로 보고되고 있다(Popelka et al., 1998). 그리고 70대의 80\%, 80대의 $92 \%$, 90대 이상 $100 \%$ 가 난청이 있는 것으로 보고되고 있다(Gates, 1990).

\section{Design and Evaluation Guide}

\subsection{Design and evaluation factors by crop}

Rural Development Administration(2008) 에서는 농작 업 환경개선의 방안을 마련하고 국내의 편이장비, 작업시스 템, 개인보호구 개발을 위한 아이템 도출을 위해 작목을 23 작목(벼, 과수 5 , 시설 6 , 화훼 2 , 축산 4)으로 분류하고 있 다. 그리고 각 작목에 해당되는 편이장비로 벼 27종, 과수 130 종, 노지채소 130 종, 시설채소 156 종, 화훼 55 종, 인삼 22 종, 버섯 43종, 축산 75 종 등 총 562종류의 장비를 명칭 에 따라 정리하여 제시하고 있다. Figure 1은 농촌에서 사용 중인 농작업 편이장비의 예를 제시한 것이다.
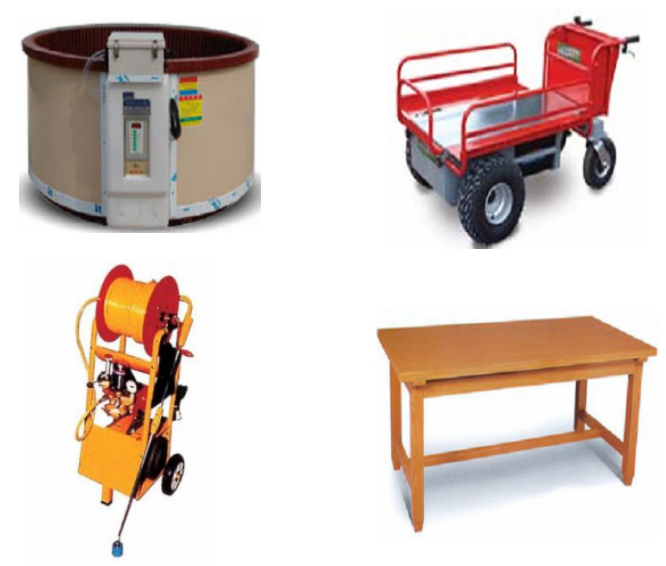

Figure 1. Example of farm working convenient equipments

본 연구에서는 유사한 작업 절차를 나타내는 작목을 통 합하여 4 가지로 분류하였다. 작업에 따라 필요한 편이장비 를 기능별로 분류하고 분류된 장비의 구성요소 중에서 인 간공학적 접근이 필요한 요소들을 추출하였다(Table 1). 작 
Table 1. Farm working convenient equipment and approach part

\begin{tabular}{|c|c|c|c|c|}
\hline Crop & Task & Convenient equipment & Approach part & Remark \\
\hline \multirow{5}{*}{ Rice } & Germination & Germinator & Control panel & \\
\hline & Transplanting & Conveyer & Frame size & \\
\hline & $\begin{array}{l}\text { Tillage } \\
\text { Consolidation } \\
\text { Management }\end{array}$ & Ditcher, Plow, Sprayer & Control lever & \\
\hline & Yield, Transportation & Power(Manual) cart & $\begin{array}{l}\text { Frame size } \\
\text { Shape } \\
\text { Control lever }\end{array}$ & \\
\hline & Seed processing & Thresher & Control lever & \\
\hline \multirow{5}{*}{ Orchard } & Fertilization & Cross fertilization kit & Frame Size, Weight & \\
\hline & Pruning & $\begin{array}{l}\text { Scissors, Ladder } \\
\text { Multipurpose work cart }\end{array}$ & Frame Size, Weight, Shape & \\
\hline & Preventing & Weeder, Sprayer & $\begin{array}{l}\text { Handle, Control lever } \\
\text { Equipment weight }\end{array}$ & \\
\hline & Yield, Transportation & $\begin{array}{l}\text { Power(Manual) cart } \\
\text { Ladder, Conveyer }\end{array}$ & Frame size, Shape & \\
\hline & Screening, Packaging & $\begin{array}{l}\text { Grader } \\
\text { Packing machine }\end{array}$ & $\begin{array}{l}\text { Control panel, } \\
\text { Frame size }\end{array}$ & \\
\hline \multirow{4}{*}{ Horticulture } & $\begin{array}{l}\text { Transplantation } \\
\text { Setting, Seeding }\end{array}$ & $\begin{array}{l}\text { Tray } \\
\text { Groove making tool } \\
\text { Farming chair }\end{array}$ & $\begin{array}{l}\text { Frame size, Shape } \\
\text { Tool Weight }\end{array}$ & \multirow{4}{*}{$\begin{array}{l}\text { Includes } \\
\text { - Vegetable } \\
\text { - Flower } \\
\text { - Special purpose crops }\end{array}$} \\
\hline & Management & $\begin{array}{l}\text { Sprayer } \\
\text { Weeder }\end{array}$ & $\begin{array}{l}\text { Equipment weight } \\
\text { Shape }\end{array}$ & \\
\hline & Yield, Transportation & $\begin{array}{l}\text { Power(Manual) cart } \\
\text { Lift cart } \\
\text { Conveyer } \\
\text { Farming chair } \\
\text { Harvest assistive equipment }\end{array}$ & $\begin{array}{l}\text { Control panel } \\
\text { Frame size } \\
\text { Shape } \\
\text { Equipment Weight } \\
\text { Control lever }\end{array}$ & \\
\hline & Screening, Packaging & $\begin{array}{l}\text { Grader } \\
\text { Work table } \\
\text { Packing machine }\end{array}$ & $\begin{array}{l}\text { Frame size } \\
\text { Shape } \\
\text { Control panel }\end{array}$ & \\
\hline \multirow{4}{*}{ livestock } & Feeding & Power(Manual) cart & $\begin{array}{l}\text { Control panel } \\
\text { Frame size } \\
\text { Shape } \\
\text { Equipment Weight } \\
\text { Control lever }\end{array}$ & \multirow{4}{*}{$\begin{array}{l}\text { Includes } \\
\text { - Poultry farm }\end{array}$} \\
\hline & Prevention & $\begin{array}{l}\text { Sprayer } \\
\text { Smoke screen equipment }\end{array}$ & $\begin{array}{l}\text { Equipment weight } \\
\text { Shape }\end{array}$ & \\
\hline & Control & Tester, Syringe & $\begin{array}{l}\text { Control panel } \\
\text { Frame size } \\
\text { Shape }\end{array}$ & \\
\hline & Cleaning & $\begin{array}{l}\text { Washer } \\
\text { Multipurpose work cart }\end{array}$ & $\begin{array}{l}\text { Frame size } \\
\text { Shape } \\
\text { Weight } \\
\text { Control lever }\end{array}$ & \\
\hline
\end{tabular}


목별로 벼는 벼(Rice)로 분류하고, 사과, 배, 복숭아, 포도, 감귤 등의 과수작목은 과수(Orchard)로 분류하였다. 또 한 수박, 딸기, 토마토, 참외, 고추, 국화, 인삼, 버섯 등은 원예(Horticulture)로 한우, 낙농, 양돈, 양계 등은 축산 (livestock) 으로 분류하였다. 각 작목은 $4 \sim 5$ 단계의 작업으 로 나눌 수 있으며, 작업별로 사용되는 편이장비가 다수 있 으나 기능별로 구분하면 1 5종류의 기능의 가진 편이장비 가 사용되고 있는 것으로 조사되었다. 각 장비에서 노화로 인한 기능 변화를 고려하여 설계되어야 하는 요소를 분석하 면 컨트롤 패널 (Control panel), 장비의 높이, 폭 등의 장비 크기(Frame size), 손잡이 등의 형태(Shape), 조작 레버 (Control lever), 장비의 무게(Equipment weight)로 나타 났다.

Table 2는 노화에 의해 저하된 기능을 반영하여야 하는 편이장비의 구성요소와 신체적, 인지적, 감각적 기능과의 관 계를 나타낸 것이다. 는 편이장비의 설계를 위해 반드시 반영되어야 하는 기능이며, $\boldsymbol{\Delta}$ 는 반드시 반영할 필요는 없으 나 반영하면 좋은 기능임을 표시한 것이다. 컨트롤 패널의 표시 부분을 예로 들면, 각 부분은 정밀한 동작이 어려운 노 인의 신체적 기능에 맞게 설계되어야 하고, 조작버튼 등과 피드백 신호는 시각의 기능과 청각적 기능을 반드시 고려하 여야 하며, 조작시 필요한 절차와 방법은 인지적 기능의 고 려를 추천함을 의미한다.

Table 2. The function which is necessary to design and evaluation

\begin{tabular}{|c|c|c|c|}
\hline Part $\quad$ Function & Physical & Cognitive & Sensory \\
\hline Control panel & 0 & $\Delta$ & 0 \\
\hline Control lever & 0 & O & $\Delta$ \\
\hline Frame size & O & - & - \\
\hline Shape & O & - & $\Delta$ \\
\hline Equipment(tool) weight & 0 & - & - \\
\hline
\end{tabular}

\subsection{Guide}

컨트롤 패널, 컨트롤 레버, 프레임 크기, 형태, 무게 등 편 이장비의 각 부분 설계 및 평가를 위해 선행 연구와 자료를 종합하여 다음과 같이 지침을 제안한다. 지침의 제안을 위해 참고한 문서 중 Size Korea(2011)의 자료는 60 69세의 고령자를 기준으로 한 5\%tile에서 $95 \%$ tile의 치수이다.

\subsubsection{Control panel}

컨트롤 패널의 위치

(1) 패널은 접근하기 쉽고 찾기 쉬운 곳에 설치하여야 한다.

(2) 장비와 일체형으로 설계되면 좋으나 설치가 어려운 경 우 가능한 장비와 가까운 곳에 설치한다.

(3) 패널은 눈 높이에 맞추어 설치되어야 하며, 이 값은 1344.0 1594.5mm이다(Size Korea, 2011).

\section{조작버튼}

(1) 버튼의 크기는 검지손가락 끝 너비보다 크게 설계되어 야 한다.

(2) 60 69세 고령자의 검지손가락의 너비는 15.5 20.4 $\mathrm{mm}$ 이다(Size Korea, 2011).

표시창

(1) 표시되는 정보는 적색이나 황색과 같은 장파장의 빛에 너지를 사용한다((Weale, 1986; Coren and Girgus, 1972; Lee and Lee, 2006).

(2) 표시창을 통해 제시되는 정보는 읽기에 충분한 밝기가 유지되어야 하며, 청년층의 사용자를 고려한 설계일 때 보다 최소 $60 \%$ 이상 크게 설계되어야 한다(Reading, 1972; Corso, 1981).

(3) 표시창에 제시되는 내용은 충분한 정적 상태를 유지하 여야 한다(Reading, 1972).

\section{작동음 및 경고음}

(1) 일반적인 청각신호는 200 5,000Hz의 주파수를 사용 하도록 권장하나 고령자를 고려하여 $2,000 \mathrm{~Hz}$ 이하 의 저주파 영역의 음을 사용한다(Popelka and Wiley, 1998).

(2) 주변의 다른 소음과 구별될 수 있게 설계되어야 한다.

(3) 음의 지속시간은 0.5 1초 동안 유지되어야 한다.

\section{작동방법 및 절차}

(1) 작동방법 및 절차는 복잡하지 않아야 한다(Craik and Tulving, 1975; Wechsler, 1987; Craik, 1991).

(2) 기억하기 어려운 작동방법 및 절차는 장비에 그 절차를 표시하거나, 간단한 설명서를 추가로 부착하여야 한다.

\subsubsection{Control lever}

레버의 위치

(1) 레버는 사용자가 편하게 앉거나, 서서 작동할 수 있는 위치에 설치한다.

(2) 앉아서 작업하는 경우 레버는 앉은 팔꿈치의 높이로 설 
계를 권장하며, 그 높이는 앉은 면에서 191.0 279.5 mm이다(Size Korea, 2011).

(3) 선 작업의 경우 레버는 허리 높이로 설계를 권장하며, 그 높이는 878.0 1068.5mm이다.

레버의 형태

(1) 레버는 사용목적에 따라 서로 다른 형태의 설계를 권장 한다.

(2) 레버 손잡이의 지름은 26.9 35.1mm으로 설계한다 (Size Korea, 2011).

\section{레버의 동작}

(1) 레버의 작동범위는 팔 동작범위를 고려하여 설계한다.

(2) 레버의 조작범위는 전후방향 $350 \mathrm{~mm}$ 이하, 가로방향 $950 \mathrm{~mm}$ 이하를 추천한다.

(3) 일반적으로 조작에 적당한 힘은 전후방향 약 10 $130 \mathrm{~N}$, 가로방향 약 $10 \sim 90 \mathrm{~N}$ 이나 고령자의 경우 이보 다 $30 \%$ 정도 작게 설계되어야 한다(Larsson, 1978; Danneskiod-Samson et al., 1984; Vandervoort, 1992).

(4) 레버조작에 따른 장비의 동작은 다음 Table 3 기준에 의한 설계를 추천한다.

Table 3. Handle operational direction and arrangement (Im, 2004)

\begin{tabular}{c|c|c}
\hline $\begin{array}{r}\text { Operation } \\
\text { method }\end{array}$ & Positive & Negative \\
\cline { 2 - 3 } $\begin{array}{c}\text { Operation } \\
\text { direction }\end{array}$ & $\begin{array}{c}\text { Operation which is } \\
\text { more activity } \\
\text { direction }\end{array}$ & $\begin{array}{c}\text { Operation which is } \\
\text { more passive } \\
\text { direction }\end{array}$ \\
\hline \multirow{2}{*}{$\begin{array}{c}\text { Handle operation } \\
\text { direction }\end{array}$} & Upward & $\begin{array}{c}\text { Downward } \\
\text { Right } \\
\text { Push }\end{array}$ \\
\hline
\end{tabular}

\subsubsection{Frame size}

장비의 높이

(1) 서서 작업하는 테이블의 높이는 팔꿈치 높이를 기준 하며, 바닥에서 862.0 992.0mm에서 설계되어야 한 다(Size Korea, 2011).

(2) 앉은 작업에서 필요한 테이블은 앉은 팔꿈치 높이를 기준으로 하며, 이는 Size Korea(2011)의 자료에서 앉은 오금 높이에 앉은 팔꿈치 높이를 더하여 계산한다. 이 값은 514.5 687.0mm이다(Size Korea, 2011).

(3) 동력식 또는 수동식 운반수레의 손잡이 부분 높이는 허리 높이를 기준으로 878.0 1068.5mm를 추천한다
(Size Korea, 2011).

장비의 너비(간격)

(1) 전정, 전지 등에 사용되는 가위의 손잡이 사이의 너비 는 손너비 보다 작아야 하며, 이 값은 72.0 91.0이다 (Size Korea, 2011)

(2) 사다리 단 사이의 간격은 발길이 정도를 추천하는데 217.5 261.5mm로 설계되어야 한다(Size Korea, 2011).

(3) 두 팔을 벌려 잡아야 하는 손잡이 사이의 간격은 어 깨 너비 정도의 간격으로 설계되어야 하는데, 이 값은 324.5 404.5mm이다(Size Korea, 2011).

\subsubsection{Shape}

손잡이의 형태

(1) 손잡이의 길이는 손 너비를 기준으로 하며 최소 91.1 $\mathrm{mm}$, 최대는 특별한 제한이 없다.

(2) 손잡이의 지름은 26.9 35.1mm으로 설계한다(Size Korea, 2011).

\subsubsection{Equipment weight}

\section{장비의 무게}

(1) ILO (International Labor Organization)의 중량물 취 급 기준에 따르면 20 35세 남자의 경우 $24 \mathrm{~kg}$, 여자 의 경우 $14 \mathrm{~kg}$ 을 권고하고 있다. 고령자의 경우 근력 감소의 영향을 고려하여 이보다 $30 \%$ 정도 작은 약 16 $\mathrm{kg}, 8.4 \mathrm{~kg}$ 을 추천한다(Larsson, 1978; DanneskiodSamson et al., 1984; Vandervoort,1992).

\section{수공구의 무게}

(1) 우리나라 20대 남성의 경우 수공구의 무게가 $800 \mathrm{~g}$ 이상인 경우 피로 발생 시점이 급격히 빨라진다(Song, et al., 1996). 고령자의 경우 이와 관련한 연구는 없으 나 이와 유사한 연구를 참고하여 이보다 15 30\% 정 도 작은 값을 추천한다(Larsson, 1978; Son and Shin, 2002).

\section{Results}

농촌지역 초고령화 현상은 농작업에 있어서도 안전사고와 근골격계 질환 환자 증가와 같은 문제들을 야기하고 있다. 그러함에도 불구하고 농촌지역 고령자들을 위한 편이장비 개발에 대한 연구는 미비한 실정이다. 본 연구에서는 고령자 
를 위한 농작업 편이장비 설계와 평가를 위한 지침을 마련하 기 위하여 노화의 영향을 신체적, 인지적, 감각적 기능으로 분류하여 각 각에 대하여 그 현상 및 특성을 조사하였다. 그 리고 유사한 절차에 따라 수행되는 작목을 통합하여 네 가지 로 분류하고 각 작목에 필요한 편이장비를 기능별로 분류하 였다. 분류된 장비의 설계와 평가요소 중에서 인간공학적 접 근이 필요한 요소들을 추출하였다. 컨트롤 패널, 컨트롤 레 버, 장비 크기, 형태, 장비의 무게가 노화에 따른 영향을 고 려하여 설계되어야 하는 항목으로 도출되었으며, 본 연구에 서는 이들에 대한 설계 및 평가 지침을 제안하였다. 제안된 설계평가 지침은 농작업 편이장비 설계자들은 물론 평가를 수행하는 전문가들이 손쉽게 활용할 수 있을 것으로 기대 한다.

\section{Acknowledgements}

This work was funded by Korea Nazarene University.

\section{References}

Amrhein, P. C., Stelmach, G. E. and Goggin, N. L., Age differences in the maintance and restructuring of movement preparation, Psychology and aging, 6, 451-466, 1993.

Brown, S. H., Control of simple arm movement in the elderly, Changes in sensory motor behavior in aging, 27-52, 1996.

Cho, H. Y. and Kim, G. B., A study on slowing in movenent of the elderly, The Korean Journal of Physical Education, 39(3), 325-337, 2000.

Coren, S. and Girgus, J., Density of human lens pigmentation: In vivo measure over an extended age range, Vision Research, 12, 343-346, 1972.

Corso, J. F., Aging sensory systems and perception, Praeger Publishers, New York. 1981.

Craik, F. I. M. and Tulving, E., Depth of processing and retention of words in episodic memory, Journal of Experimental Psychology, 104, 268 $-294,1975$.

Craik, F. I. M., Memory functions in normal aging. In T. Yanagihara and R. C. Petersen (Eds), Memory disorders: Research and Clinical Practice, Van Nostrand Reinhold, New York, 1977.

Danneskiod-Samson, et al., Muscle stength and functional capacity in 78-81year old men and women, European Journal of Applied Physiology, 52(3), 310-314, 1984.

Gates, G., et al. Hearing in the elderly:the Framingham Cohort, Part I. Basic audiometric test results, Ear and Hearing, 11, 247-256, 1990.

Goldstein, E. B., Sensation and perception, Wadsworth, California, 1984.
Gyeongsangnam-do Inhabitants Daily Report, Old person safety accident, http://www.idomin.com/news/articleView.html(retrieved June 14, 2011).

Im Y. W., Design Ergonomics, Mijinsa, 1992.

Korea Consumer Agency, Agricultural machine safety condition survey, 2009.

Lasson, L., Morphological and functional characteristics of the ageing skeletal muscle in man. A cross sectional study, Acta physiology Scandinavica, 457, 1-36, 1978.

Lee, N. H. and Kim, G. H., The somatotype characteristic and clothing life of the elderly, Proceedings of the 2007 fall conference on Korea fashion and custom design association, 36-39, 2007.

Lee, Y. J. and Lee, H. S., Characteristics of color perception about yellow and blue with human lens coloration, Info Design Issue, 73-83, 2006.

McDowd, J. M. and Shaw, R. J., Attention and aging: A functional perspective. In F.I.M. Craik and T.A. Salthouse(Eds), Handbook of Aging and Cognition II. Erlbaum, New Jersey, 2000.

Park, H. J., Cho, S. H. and Cho, S. J., A Study on hearing status of the elderly population in Jeonnam, Audiology, 2, 58-61, 2006.

Popelka, M. M., et al. Low prevalence of hearing aid use among older adult with hearing loss:the epidemiology of hearing loss study, Journal of the American Geriatrics Society, 46, 1075-1087, 1998.

Park, T. J., Cognitive Neural Mechanisms of Aging, Proceedings of the 2004 winter conference on Korea Experimental Psychologycal Society, 33-39, 2004

Reading, W. M., Visual resolution as measured by dynamic and static tests, Pflügers Archiv European Journal of Physiology, 333, 17-26, 1972.

Rural Development Administration, Handbook of farm working convenient equipment and Individual protection I, 2008.

Schneider, B. A. and Pichora-Fuller, M. K., Implications of perceptual deterioraton for cognitive aging research, In F.I.M. Craik and T.A Salthouse(Eds), Handbook of Aging and Cognition II. Erlbaum, New Jersey, 2000

Seo, S. R. and Lee, S. D., Evaluation of labor adaptation of middle and old aged bhy finger reaction, Journal of the Ergonomics Society of Korea, 11(1), 31-38, 1992

Size Korea, http://sizekorea.kats.go.kr(retrieved June 14, 2011).

Son, B. C. and Shin, S. H., A Study on Wrist-Twisting Torque for Korean Females, 21(4), 67-84, 2002.

Son, B. C., Lee, K. S. and Shin, S. H., "Improvement of assistive equipment using Ergonomics for agricultural works", Proceedings of the 9th Pan-Pacific Conference on Ergonoimcs, SS3-146, Kaohsiung. Taiwan. 2010.

Song, H. Y., et al. "The influence study of upper arm postural Tremer of hand tool weight on static posture", Proceedings of the Spring Conference on Associate of Korea Industrial Engineering, 1(pp. 151 -157), Seoul. Korea. 1996.

Statistics Korea, 2007 Agriculture and fishing industry person basic statistical survey, 2008.

Statistics Korea, 2010 Old person statistics, 2010.

Stelmach, G. E., Amrhein, P. C. and Garcia-Colera, A., Age difference in bimanual coordination, Journal of Gerontology, 43, 18-23, 1988. 
Stelmach, G. E., Goggin, N. L. and Garcia-Colera, A., Movement specification time eith age, Experimental Aging Research, 13, 39-46, 1987.

Vandervoort, D., Quality of social support in mental and physical health, Current Psychology,18(2), 205-221, 1992.

Voie, D. L. and Light, L. L., Adult age differences in repetition priming: A meta analysis, Psychology and Aging, 9, 539-553, 1994.

Weale, R., Aging and vision, Vision Research, 26, 1507-1512, 1986.

Wechsler, D., Wechsler Memory Scale-Revised manual San Antonio, The Psychology Corporation, Texas, 1987.

Winfield, A. and Kahana, M. J., The dynamics of memory retrieval in order adulthood, Canadian Journal of Experimental Psychology, 56, 187-199, 2002

Yonelinas, A. P., The nature of recollection and familiarity: A review of 30 years of research, Journal of Memory and Language, 46, 441-517, 2002.

Zacks, R. T., Hasher, L. and Li, K. Z. H., Human memory, In F.I.M. Craik and T.A. Salthouse(Eds), Handbook of Aging and Cognition II. Erlbaum, New Jersey, 2000

\section{Author listings}

Byung Chang Son: bcson@kornu.ac.kr

Highest degree: $\mathrm{PhD}$, Department of Industrial Engineering, Keimyung

University

Position title: Associate Professor, Department of Rehabilitation

Engineering, the University of Korea Nazarene

Areas of interest: Aging, Disability, Product Design
Seung Heon Shin: shs219@kmu.ac.kr

Highest degree: $\mathrm{PhD}$, Department of Management Engineering, Keio University

Position title: Professor, Department of Management Engineering, the University of Keimyung

Areas of interest: Human Factors, Safety, Aging

Date Received : 2011-07-06

Date Revised :2011-07-26

Date Accepted : 2011-07-27 